\title{
Regulation of oxidative stress and lipid peroxidation in PTU induced mice, treated with Pyrroloquinoline quinone (PQQ)
}

\author{
Narendra Kumar ${ }^{1 *}$, Anand $\mathrm{Kar}^{2}$ \\ ${ }^{1,2}$ Thyroid Research Unit, School of Life Sciences, Devi Ahilya University, Takshashila Campus, Indore, M. P., \\ 452017, India.
}

\begin{abstract}
Hitherto unknown effects of Pyrroloquinoline quinone (PQQ) in 6-n-propyl-2-thiouracil (PTU)induced oxidative stress and lipid peroxidation were investigated in adult mice. Animals received either PTU $(0.05 \%$ in drinking water) alone for 5 weeks or PTU + three different concentrations of $P Q Q$, after which alterations in tissue lipid peroxidation (LPO) and in enzymatic activities of superoxide dismutase (SOD) and catalase (CAT) and in glutathione (GSH) content were evaluated in two different organs such as liver and heart. Simultaneously, concentrations of serum glucose, total cholesterol, glutamate oxaloacetate transaminase (SGOT), glutamate pyruvate transaminase (SGPT), creatinine and urea were measured in serum. PTU administration enhanced the tissue LPO, serum SGOT, SGPT, total cholesterol, creatinine and urea with a parallel decrease in serum glucose and tissue antioxidants such as SOD and CAT in both the organs. When $P T U$ treated animals received $P Q Q$, these adverse effects were ameliorated. Out of three different doses of $P Q Q$ (1, 5 and $10 \mathrm{mg} / \mathrm{kg} / \mathrm{d}$, i.p. for 6 days), $10 \mathrm{mg} / \mathrm{kg}$ body weight was found to be the most effective and antiperoxidative in nature, as it maximally reduced the LPO of liver and heart, with a parallel increase in cellular antioxidants. Findings from this study revealed for the first time, that PQQ has the potential to ameliorate PTU-induced oxidative damage in liver and heart, indicating the possible beneficial effect of the test compound in regulating hypothyroidism.
\end{abstract}

Keywords: $L P O$, mice, oxidative stress, $P T U, P Q Q$.

\section{Introduction}

Pyrroloquinoline quinone (PQQ), an anionic, water soluble compound was initially isolated from cultures of methylotropic bacteria as a crystalline acetone adduct and was proposed to be a cofactor of many bacterial primary alcohol dehydrogenases, methanol dehydrogenase, glucose dehydrogenase and aldehyde dehydrogenase ( Duine et al., 1981; Salisbury et al., 1979; Ameyama et al., 1981; Van-Kleef et al., 1988). This compound has been attributed with multiple physiological functions such as regulation of electron transport system (Kobayashi et al., 2005), enhancing the adaptability of microbes ( Khairnar et al., 2007), improving the growth of plants ( Choi et al., 2008) and stimulating the production of nerve growth factor (Yamaguchi et al., 1993), thus presenting a wide application prospect in pharmaceutical, agriculture and food industries (Andrea et al., 1999; Rucker et al., 2009; Misra et al., 2012).

Recently, it has been reported that PQQ scavenges reactive oxygen species (ROS) (Misra et al., 2004, Rajpurohit et al., 2008) and protects cells from oxidative stress-induced damage, effectively improves the activities of free radical scavenging enzymes and decreases the levels of free radicals as well as lipid peroxidation (LPO) (Zhu et al., 2004; Wu et al., 2008; Qiu et al., 2009). In vitro studies showed that PQQ protects isolated liver mitochondria from damage after oxidative stress and scavenges superoxide radicals (Smidt et al., 1991; Bishop et al, 1998; He et al., 2003). Previous in vivo studies of I/R injury in rats also suggested that PQQ reduces myocardial infarct size and improves cardiac function (Zhu et al., 2004).

Both in vivo and in vitro studies have shown that PQQ can protect against several types of oxidative damage and toxic injury, as well as stroke damage and irradiation injury. (Hamagishi et al., 1990; Smidt et al., 1991; Aizenman et al., 1992; Bishop et al., 1994; Jensen et al., 1994; Ouchi et al., 2009; Xiong et al., 2011). Despite all these beneficial actions of PQQ, no attempt was made so far by any worker to evaluate its role in the regulation on the oxidative damage in hypothyroidic conditions.

Thyroid hormones are involved in the regulation of numerous body functions including lipid and carbohydrate metabolism, oxygen consumption and several physiological functions such as development, reproduction and growth (Kundu et al., 2006). Alterations in their normal levels cause some biochemical and clinical abnormalities such as hypothyroidism. Further, thyroid dysfunction is postulated to be closely related to ROS formation, which might account for thyroid hormone-induced tissue damage. It is also known that thyroid dysfunction increases LPO reactions and ROS (Venditti and Di-Meo, 2006; Messarah et al., 2010). LPO is an autocatalytic mechanism leading to oxidative destruction of cellular membranes (Asayama and Kato, 1990). Such destruction can lead to cell death and to the production of toxic and reactive aldehyde metabolites called 
free radicals, where malondialdehyde (MDA) is the most important product. It is further known that ROS lead to the oxidative damage of biological macromolecules, including lipids, proteins and DNA (Das and Chainy, 2001).Some reports also indicate the development of oxidative stress and cardiovascular diseases with hypothyroidism (Das and Chainy, 2001; Venditti and DiMeo, 2006; Messarah et al., 2010; Knapp et al., 2013). Since PQQ is known to regulate oxidative damage and hypothyroidism is associated with oxidative stress (Venditti and Di-Meo 2006; Jena et al. 2012), it was thought that the compound may ameliorate hypothyroidism induced oxidative damage also.Because of this presumption and keeping in mind the unavailability of scientific literature on the role of PQQ in the regulation of thyroid dysfunctions, the present study was undertaken to evaluate the role of PQQ, if any, in ameliorating 6-n-propyl-2-thiouracil (PTU) induced oxidative damage in different organs.

\section{Animals}

\section{Materials and Methods}

Swiss albino mice, weighing $30 \pm 2$ gm were housed in polypropylene cages in a standard photoperiod (14 h light: $10 \mathrm{~h}$ dark) and temperature $\left(27 \pm 1^{\circ} \mathrm{C}\right)$ controlled room with the provision of laboratory feed (Gold Mohur feed, Hindustan Lever Limited, Mumbai, India) and water ad libitum. Animals were maintained in accordance with the guidelines of committee for the purpose of control and supervision of experiments on animals (CPCSEA), Ministry of Social justice and Empowerment, Govt. of India.

\section{Chemicals}

PQQ was purchased from Quality of life lab, USA; PTU was obtained from Sigma-Aldrich chemicals (St. Louis, MO, USA). Ellman's reagent, m-phosphoric acid, thio-barbituric acid (TBA), sodium dodecyl sulphate, tri carboxylic acid (TCA), hydrogen peroxide $\left(\mathrm{H}_{2} \mathrm{O}_{2}\right)$ were obtained from E. Merck Ltd., Mumbai, India. Kits for the estimation of different lipids, glucose, urea, creatinine and glucose were procured from Transasia Bio-Medicals ltd., Solan, India. All other chemicals were of reagent grade and obtained from Sisco Research Laboratories Pvt. Ltd., Mumbai, India.

\section{Experimental design}

Five groups of 7 each healthy male mice were established. Group I animals receiving simple drinking water served as control, whereas those of group II, III, IV and V received only PTU $(0.05 \%$ in drinking water for 5 weeks) (Guerrero et al., 1999; Messarah et al., 2010; Jena et al., 2012). On 30 day, animals of group III, IV and V received different doses of PQQ $(1,5$ and $10 \mathrm{mg} / \mathrm{kg} /$ day for six days, respectively) along with PTU as administered to group II animals. Experiment was continued for 5 consecutive weeks. On the day of termination $\left(36^{\text {th }}\right.$ day), over night fasted animals were sacrificed under mild anesthesia, blood from each animal was collected and serum was separated for the estimation of different biochemical parameters including serum concentrations of glutamate oxaloacetate transaminase (SGOT), glutamate pyruvate transaminase (SGPT), glucose, creatinine, urea and total cholesterol. After exsanguinations, liver and heart tissues were removed quickly, washed with phosphate buffered saline (PBS) and processed for the estimation of lipid peroxidation (LPO), super-oxide dismutase (SOD), catalase (CAT) activities and glutathione (GSH) content.

\section{Biochemical estimations}

Liver and heart tissues were homogenized in PBS (0.1M, pH 7.4), centrifuged at 15,000g for $30 \mathrm{~min}$ at $4^{\circ} \mathrm{C}$ and the supernatant was used for subsequent analysis.

\section{Lipid peroxidation (LPO)}

Lipid peroxidation level in the tissues was measured by the method of Ohkawa et al., (1979) which is based on the TBA reaction with MDA, a product formed due to the peroxidation of membrane lipids. The amount of MDA was measured by taking the absorbance at $532 \mathrm{~nm}$ (extinction coefficient, $\mathrm{E}=1.56 \times 10^{5}$ ), using a Shimadzu UV-160 spectrophotometer. LPO was finally expressed as nM MDA formed/ h/ mg protein.

\section{Super-oxide dismutase (SOD) assay}

Activity of SOD was determined following the pyrogallol auto-oxidation inhibition assay method of Marklund \& Marklund (1974). The rate of auto-oxidation is calculated from the increase in absorbance at 420 $\mathrm{nm}$. The enzyme activity was expressed as units $/ \mathrm{mg}$ protein and 1 unit is defined as the enzyme activity that inhibits auto-oxidation of pyrogallol by $50 \%$. 


\section{Catalase (CAT) assay}

Catalase activity was estimated following the method of Aebi (1983) that is based on the decomposition of $\mathrm{H}_{2} \mathrm{O}_{2}$ which is measured spectrophotometrically from the changes in absorbance at $240 \mathrm{~nm}$ which was expressed as $\mu \mathrm{M}$ of $\mathrm{H}_{2} \mathrm{O}_{2}$ decomposed $\mathrm{min}^{-1} \mathrm{mg}^{-1}$ protein

\section{Glutathione (GSH) assay}

For the estimation of tissue GSH content the protocol of Ellman (1959) was followed in which the -SH group of GSH reacts with DTNB to produce a yellow-colored 2-nitro-5-mercaptobenzoic acid and the absorbance was taken at $412 \mathrm{~nm}$. The GSH content is expressed as $\mu \mathrm{M} \mathrm{GSH} / \mathrm{mg}$ protein.

\section{Protein, glucose, total cholesterol, urea and creatinine estimations}

Protein estimation was done by the routine method of Lowry et al., (1951) using bovine serum albumin as standard and fasting serum glucose concentration was measured by glucose oxidase / peroxidase method based on the protocol of Trinder (1969), where 4-amino antipyrine and phenol reacts with glucose to produce a pink colored quinoneimine dye. The intensity of the color developed is proportional to glucose concentration in the sample, while estimations of serum total cholesterol were done using spectrometric methods of Allain et al., 1974. Urea and creatinine were estimated using the commercially available kits and protocols of Transasia biomedicals ltd. Solan, India.

\section{Serum glutamate pyruvate transaminase assay}

The method used here is of Reitman Frankel (1957) colorimetric end point reaction method. SGPT catalyzes L-alanine and $\alpha$-ketoglutarate to form pyruvate and glutamate. The pyruvate is then reacted with 2,4dinitrophenylhydarzine (2,4-DNPH-ine) to form 2,4-DNPH-one.The addition of sodium hydroxide dissolves this complex and allows 2,4-DNPH-one to be measured at $505 \mathrm{~nm}$.

\section{Serum glutamate oxaloacetate transaminase assay}

This catalyzes transfer of amino group from L-aspartate to $\alpha$-ketoglutarate with formation of oxaloacetate and glutamate. The oxaloacetate, so formed, is allowed to react with 2,4-DNPH (2,4 dinitro phenyl hydrazine) to form 2,4 dinitro phenyl hydrazone derivative, which is brown colored in alkaline medium. The absorbance of this hydrazone derivative is correlated to SGOT activity by plotting a calibration curve using pyruvate standard. The colored complex is read at $505 \mathrm{~nm}$.

\section{Statistical analysis}

Data are expressed as means \pm SEM. For the statistical evaluation, analysis of variance and Student $t$ test were used (Senedector and Cochran, 1956). A $p$ value of 0.05 or less is considered as the level of significance.

\section{Effect on LPO and antioxidants}

\section{Results}

PTU administration increased the LPO (Fig. 1.) in both liver and heart tissues significantly $(p<0.001)$; with a decrease in SOD $(p<0.001, p<0.05$ respectively); It also decreased CAT activity in both tissues significantly $(p<0.05$ for liver and $p<0.001$ for heart). There was no significant change in GSH level after PTU administration in both the tissues. Following the administration of PQQ almost all these effects of PTU were reversed. However, out of the three doses $(1,5$ and $10 \mathrm{mg} / \mathrm{kg} / \mathrm{d})$ of PQQ, $10 \mathrm{mg} / \mathrm{kg}$ body weight was found to be most effective in decreasing LPO in both the tissues $(p<0.001)$ and the percentage decreases were found to be $86 \%, 64 \%$, in liver and heart respectively; while other two doses were also found to be significantly effective. 


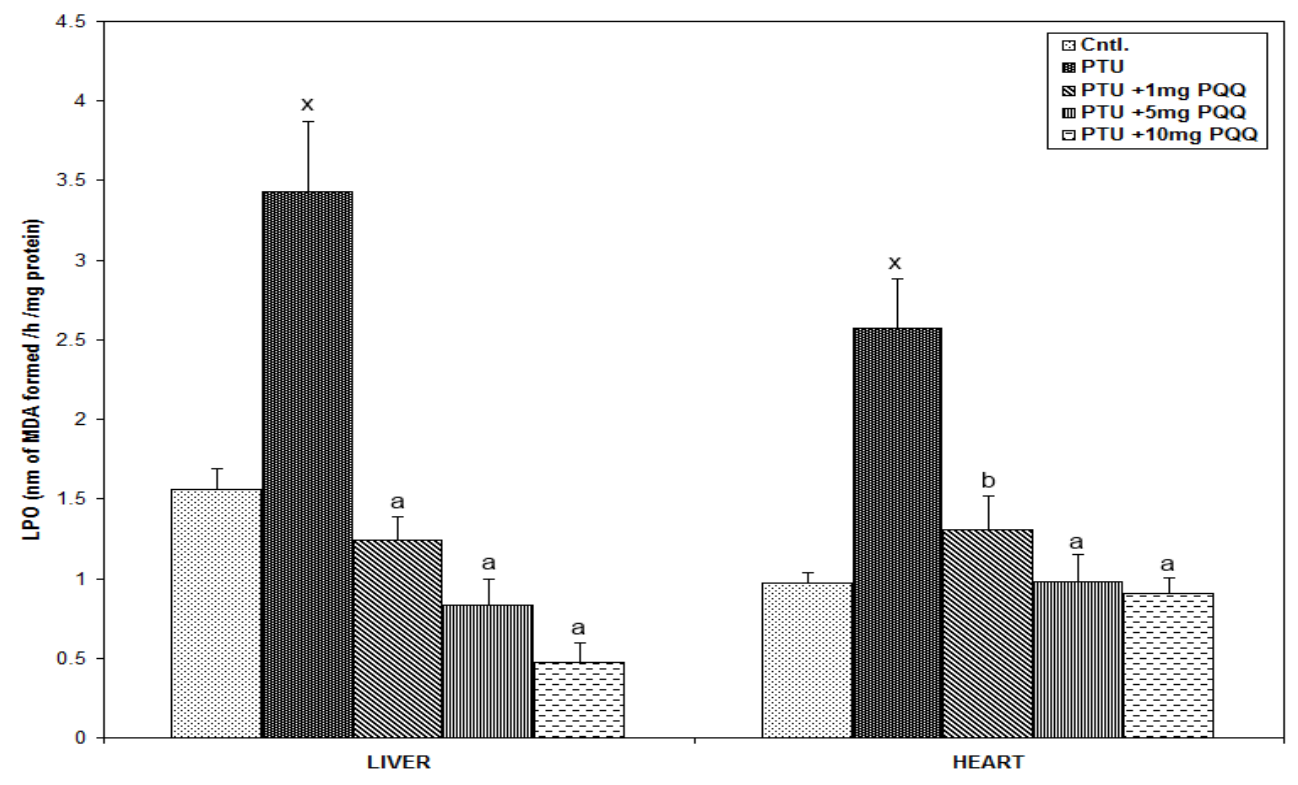

Figure 1: Effects of PQQ (1, 5 and $10 \mathrm{mg} / \mathrm{kg} / \mathrm{d}$, i.p.) for 6 days in LPO (nm of MDA formed $/ \mathrm{h} / \mathrm{mg}$ protein) of liver and heart. Data are mean \pm S.E.M. $(\mathrm{n}=7) .{ }^{\mathbf{x},} p<0.001^{\mathbf{y},} p<0.01^{, \mathbf{z}} p<0.05$ compared to the respective control values. ${ }^{\mathrm{a}} p<0.001,{ }^{\mathrm{b},} p<0.01$ and ${ }^{\mathrm{c},} p<0.05$ as compared to the respective PTU treated value. ${ }^{\mathrm{PTU}}$, Propylthiouracil, ${ }^{\mathrm{LPO}}$, Lipid Peroxidation and ${ }^{\mathrm{PQQ}}$, Pyrroloquinoline quinone.

With respect to SOD activity, again the highest dose, i.e. $10 \mathrm{mg} / \mathrm{kg}$ appeared to be most effective in both tissues ( $p<0.01$ for liver and heart) (Fig. 2.) and the percentage increases were found to be $63 \%$ and $33 \%$, respectively. Of course, other two doses were also found to be effective in liver.

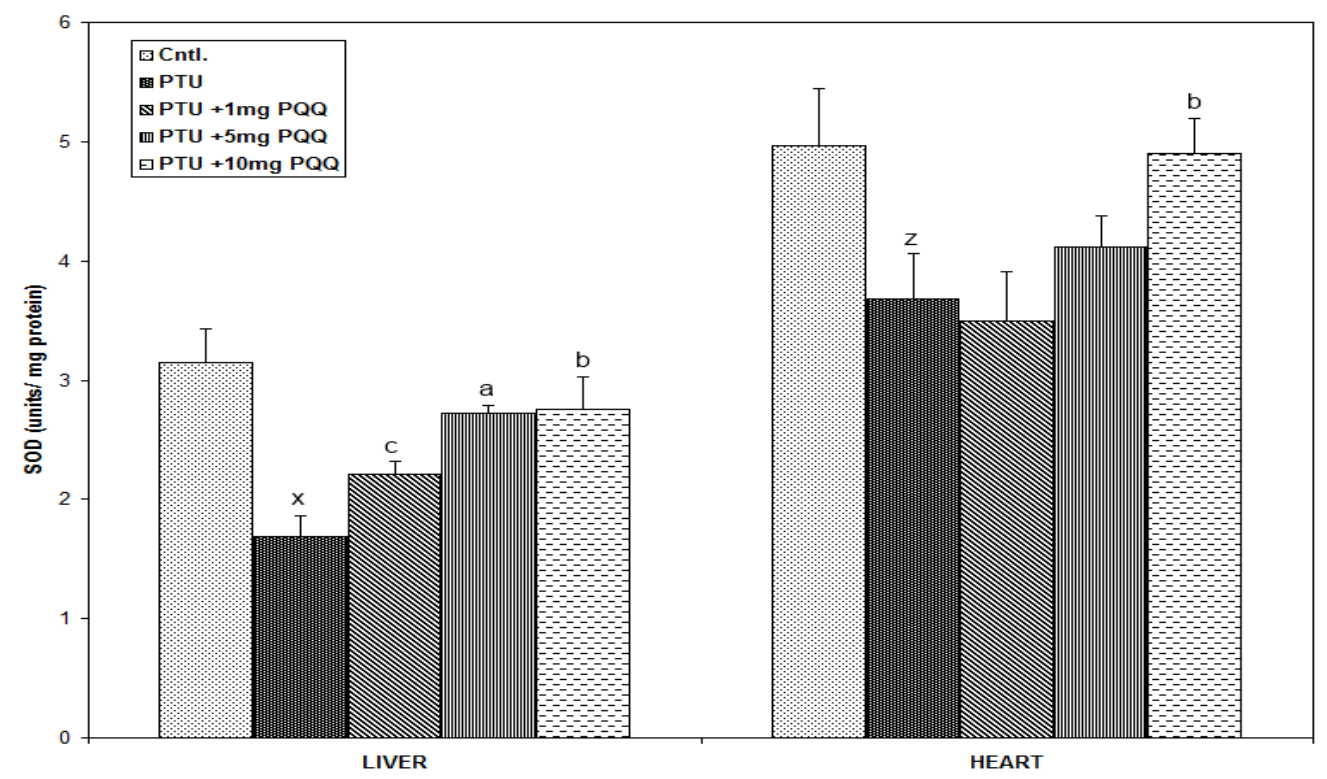

Figure 2: Effects of PQQ (1, 5 and $10 \mathrm{mg} / \mathrm{kg} / \mathrm{d}$, i.p.) for 6 days in SOD (units/ $\mathrm{mg}$ protein) of liver and heart. Data are mean \pm S.E.M. $(\mathrm{n}=7)$. ${ }^{\mathbf{x}}$, and ${ }^{\mathrm{z}} p<0.05$ compared to the respective control values. ${ }^{\mathbf{a}} p<0.001,{ }^{\mathbf{b}}, p<$ 0.01 and ${ }^{\mathrm{c},} p<0.05$ as compared to the respective PTU treated values. ${ }^{\text {PTU, }}$ Propylthiouracil, ${ }^{\text {SOD, }}$ Superoxide Dismutase and ${ }^{\mathrm{PQQ}}$, Pyrroloquinoline quinone

Catalase enzyme activity significantly increased in both the studied tissues i.e. liver and heart $(p<$ $0.05 ; p<0.001$, respectively) by the administration of $10 \mathrm{mg} / \mathrm{kg}$ body weight of PQQ (Fig. 3.) and the percentage increases were found to be $40 \%$ and $72 \%$, respectively; while other two doses were also found to be significantly effective. 


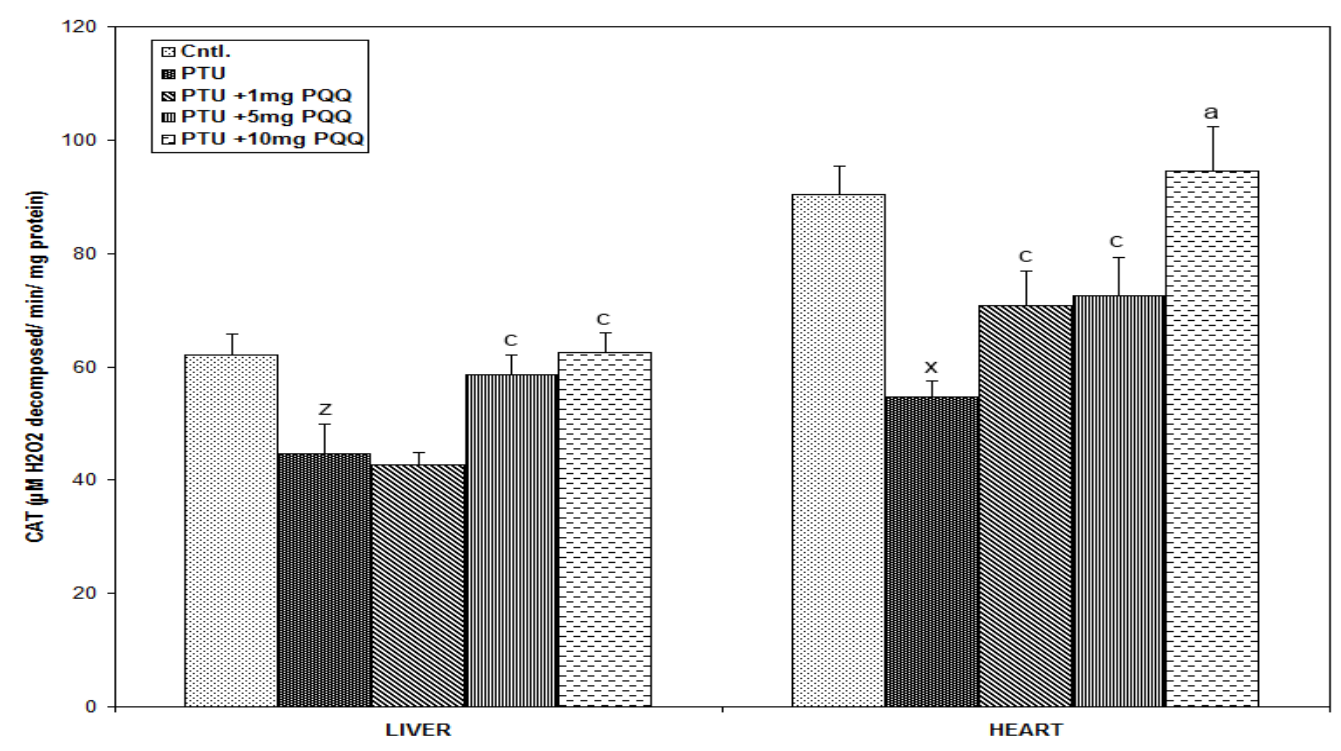

Figure 3: Effects of PQQ $\left(1,5\right.$ and $10 \mathrm{mg} / \mathrm{kg} / \mathrm{d}$, i.p.) for 6 days in CAT $\left(\mu \mathrm{M} \mathrm{H}_{2} \mathrm{O}_{2}\right.$ decomposed/ $\mathrm{min} / \mathrm{mg}$ protein) of different tissue. Data are mean \pm S.E.M. $(\mathrm{n}=7) .{ }^{\mathrm{x},} p<0.001$ and $^{\mathrm{z}} p<0.05$ compared to the respective control values. ${ }^{\mathrm{a}}{ }^{2} p<0.001$ and ${ }^{\mathrm{c},} p<0.05$ as compared to the respective value PTU treated group values. ${ }^{\text {PTU, }}$ Propylthiouracil, ${ }^{\text {CAT, }}$ Catalase and ${ }^{\mathrm{PQQ}}$, Pyrroloquinoline quinone

Although PTU did not exhibit any significant changes in GSH content in both the tissues, PQQ increased GSH content significantly ( $p<0.05$ and $p<0.001$ for liver and heart respectively) at a dose of 10 $\mathrm{mg} / \mathrm{kg}$ with a percent increase of $46 \%$ and $222 \%$ respectively. Although $5 \mathrm{mg}$ and $10 \mathrm{mg} / \mathrm{kg}$ of PQQ significantly increased the same, later concentration being the most effective one with a greater percentage (Fig. 4).

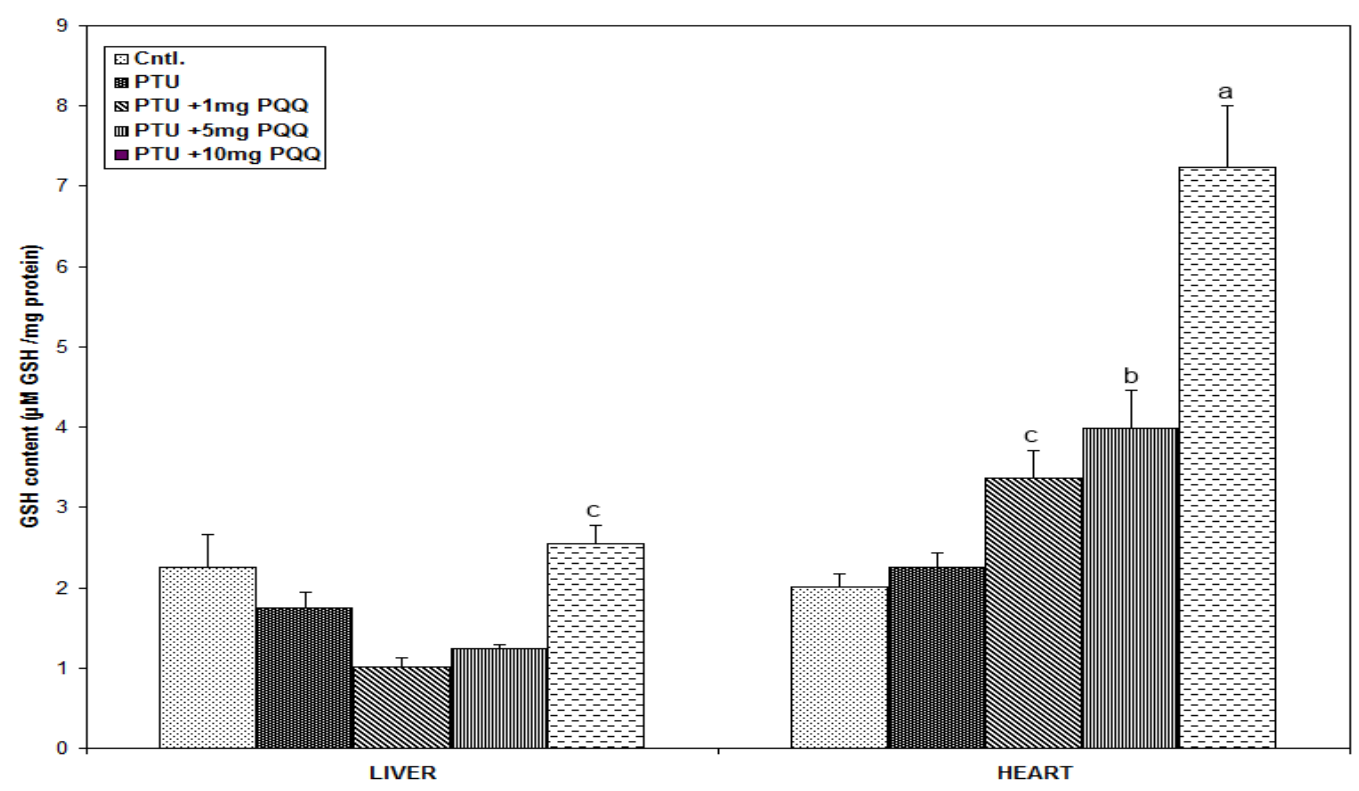

Figure 4: Effects of PQQ (1, 5 and $10 \mathrm{mg} / \mathrm{kg} / \mathrm{d}$, i.p.) for 6 days in GSH content ( $\mu \mathrm{M} \mathrm{GSH} / \mathrm{mg}$ protein) of different tissue. Data are mean \pm S.E.M. $(\mathrm{n}=7)$. ${ }^{\mathbf{b}}, p<0.01$ and ${ }^{\mathrm{c},} p<0.05$ as compared to the respective value of PTU treated group. ${ }^{\text {PTU, }}$ Propylthiouracil, ${ }^{\text {GSH, }}$ Reduced glutathione and ${ }^{\text {PQQ, }}$ Pyrroloquinoline quinone

\section{Effect on serum glucose, cholesterol and hepatic marker}

With respect to serum parameters, a significant increase in the level of total cholesterol, SGOT, SGPT, creatinine and urea was found in PTU treated animals ( $p<0.01, p<0.001, p<0.01, p<0.01$ and $p<0.001$ respectively) (Fig. 5). However, administration of $\mathrm{PQQ}$ at a dose of $10 \mathrm{mg} / \mathrm{kg}$ markedly reduced all these indices and the percentage decreases were found to be $33 \%, 74 \%, 72 \%, 59 \%$ and $56 \%$ in total cholesterol, 
SGOT, SGPT, creatinine and urea respectively. By the administration of PTU, level of serum glucose decreased significantly ( $p<0.05$ by $25 \%$ ); while by the simultaneous administration of $5 \mathrm{mg}$ and $10 \mathrm{mg} / \mathrm{kg}$ of PQQ it increased significantly ( $p<0.001$ for both, $26 \& 32 \%$ respectively). Other two doses were also found to be significantly effective.

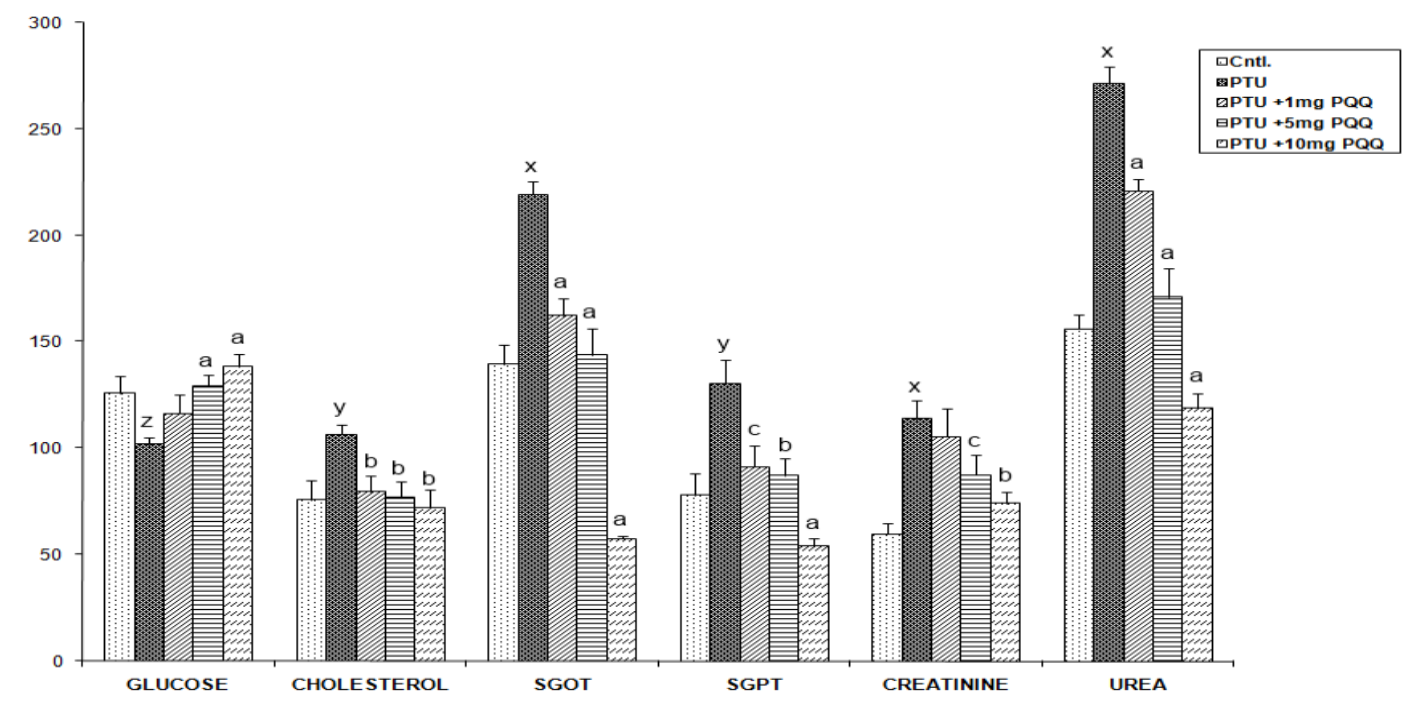

Figure 5: Effects of PQQ $(1,5$, and $10 \mathrm{mg} / \mathrm{kg} / \mathrm{d}$, i.p.) for 6 days on different serum parameters of total cholesterol (mg/dL), glucose (mg/dl), SGPT (IU/L), SGOT(IU/L), creatinine $(\mathrm{mg} / \mathrm{dl})$ and urea $(\mathrm{mg} / \mathrm{dl})$, Data are mean \pm S.E.M. $(\mathrm{n}=7) .{ }^{\mathrm{x},} p<0.001^{\mathrm{y}}, p<0.01^{\mathrm{y}}, p<0.05$ compared to the respective control values. ${ }^{\mathbf{a},} p<0.001$, ${ }^{\mathbf{b},} p<0.01$ and ${ }^{\mathbf{c},} p<0.05$ as compared to the respective PTU treated group values. ${ }^{\text {PTU, }}$ Propylthiouracil, ${ }^{\text {PQQ, }}$ Pyrroloquinoline quinone, ${ }^{\text {SGOT, }}$ Serum glutamate oxaloacetate transaminase, ${ }^{\text {SGPT, }}$ Serum glutamate pyruvate transaminase.

\section{Discussion}

Results of the present experiment clearly revealed that, PQQ has the potential in regulating the PTU induced oxidative damage in both the organs of mice and other associated problems including serum glucose, Cholesterol and some hepatic/cardiac markers.

Administration of PTU, a commonly used antithyroidic drug significantly increased lipid peroxidation in both the studied organs with a parallel decrease in the antioxidants such as SOD and CAT in the similar manner as reported earlier by others (Venditti and Di-Meo, 2006; Jena et al., 2012). However, PTU-induced animals when received PQQ simultaneously reversed these effects.

PTU inhibits functions of the thyroid hormones that are among the most important factors involved in the basal metabolic rate of almost both organs including liver and heart (Guerrero et al., 1999; Ganong, 2005). Thyroid abnormalities are also considered as physiological modulators of in vivo cellular oxidative stress. It is now well established that deficiency of thyroid hormones can lead to an oxidative stress condition in the liver and heart with a consequent lipid peroxidative response (Yilmaz et al., 2003). Further, hypothyroidism-induced dysfunction of the respiratory chain in the mitochondria leads to accelerated production of free radicals (i.e., superoxide anion, hydrogen peroxide, and hydroxyl radical as well as lipid peroxides), which consequently leads to oxidative stress (Venditti et al., 1997; Yilmaz et al., 2003; Carmeli et al., 2008).

Interestingly, in the present study, following the administration of PQQ, particularly $10 \mathrm{mg} / \mathrm{kg}$, not only LPO was reduced in almost all the studied tissues, but also levels of SOD, CAT and GSH were enhanced suggesting the antioxidative potential of the PQQ. These observations corroborate with the earlier reports, where free radical scavenging property of PQQ has been highlighted (Misra et al., 2004; Shrivastava et al., 2010).With other two concentrations of PQQ ( 1 and $5 \mathrm{mg} / \mathrm{kg}$ ) also, LPO was inhibited in the tissues of all the studied organs, with a significant elevation in SOD and CAT. Some workers suggest that hypothyroidism protects tissues against accelerated lipid peroxidation, although the data concerning oxidation / antioxidation in hypothyroidism are incomplete and contradictory (Isman et al., 2003; Venditti and Di Meo, 2006). In fact, Dariyerli et al., (2004) did not find any change in the content of malondialdehyde in rats with thiamizoleinduced hypothyroidism. However, following PQQ administration there was a significant increase in its level in all studied tissues. Hypothyroidism specifically reduces most tissues cellular thiol reserves and alters glutathione content. GSH is a well-known antioxidant that provides the major protection against cellular oxidative damages, and maintains SH level in proteins (Sies, 1999). In this experiment, GSH level remained unchanged in most tissues of PTU administered group in comparison to control as observed earlier by some other workers 
(Asayama et al., 1987; Tas et al., 2006). However, administration of PQQ increased the GSH level in both the studied organs, suggesting that the test compound has the potential to enhance cellular antioxidant status.

PQQ is highly electrophilic in nature and it reacts with many substances. It forms stable adducts with carbonyl reagents. These characteristics provide PQQ the ability to oxidize the redox modulatory site, thus conferring protection against ROS-mediated cell injury (Aizenman et al., 1992). The possibility of PQQinduced reduction in intracellular ROS levels is consistent with the hypothesis that it acts directly or indirectly as a potent free radical scavenger. Probably for this reason LPO level was normalized in PQQ treated animals. Of course its site of action, either intra-mitochondrial or in the cytoplasm, or both, is yet to be determined (Tao et al., 2007). This could be the mode of action of PQQ in the present study also.

The positive effects of PQQ were also reflected in the PTU induced animals with respect to other indices such as serum glucose, total cholesterol, creatinine and urea; particularly at a concentration of $10 \mathrm{mg} / \mathrm{kg}$. When percentage of increase and decrease in different indices were calculated, better effects were also observed at $10 \mathrm{mg} / \mathrm{kg}$, as compared to the other two concentrations.

All these observations certainly indicate the ameliorative effect of PQQ in PTU induced oxidative damage. An increase of lipid peroxidation attributed to dislipidaemia has also been observed in women with hypothyroidism (Nanda et al., 2007). Both qualitative and quantitative lipid disorders, hyperlipoproteinemia and hypercholesterolemia have been described for a long time in hypothyroidism (Wahlqvist et al., 1977). Since we also observed hypercholesterolemia with a parallel increase in tissue LPO, the observed PTU induced inccrease in tissue LPO may be considered as the result of hypothyroid condition.

In our study the elevation of both serum urea and creatinine levels in response to PTU indicates possible renal and hepatic damage. These two are considered as the major indices of impaired kidney and hepatic functions (Lindeman, 1990) and their increased level in the serum of hypothyroid rats may be due to reduction in glomerular filtration rate (GFR) (Montenegro et al., 1996). Interestingly administration of PQQ to PTU treated mice resulted in declined level of serum urea and creatinine as compared to PTU treated animals, again suggesting the protective effects of the test compound. The beneficial effect of PQQ was also reflected in the alterations in the activities of hepatic markers (SGOT and SGPT). While in PTU administered animals there was an increase in these enzyme activities, the adverse effects were reversed by simultaneous administration of PQQ.

Liver is a major target organ for thyroid hormone with important biological and medical implications (Feng et al., 2000; Simon-Giavarotti et al., 2002). Clinical diagnosis of disease and damage to the structural integrity of liver is commonly assessed by monitoring the status of serum SGOT and SGPT activities (Amin and Hamza, 2005). In fact, enzymatic activities of SGOT and SGPT are considered as sensitive serological indicators of liver toxicity. In our study these parameters were significantly altered by PTU, suggesting that PTU might cause critical injury to liver. These observations along with change in LPO, indicated that hypothyroidism may lead to the overproduction of free radicals, which in turn exert deleterious effects on liver. As following the administration of PQQ in PTU administered mice, serum SGOT and SGPT levels were reduced to near normal values, the positive effects of the test drug was again supported.

With respect to the alterations in different lipid contents, PTU administration increased the total cholesterol concentrations in PTU treated animals. Earlier Plisetskaya et al., (1983) have shown that chemical thyroidectomy by the treatment of thiourea or 6-PTU causes either depletion or accumulation of liver lipids. It is also understood that the variations in the serum total cholesterol is very often related to thyroid dysfunctions altering cholesterol biosynthesis. The most noticeable fact is that hypothyroidism results in the accumulation of cholesterol in the body (Norris, 1969; Sheridan and His-Kao, 1998). Hyperlipedemia and hypercholesterolemia may result from increased mobilization of body fat reserves due to increased thyrotropic hormone level and hypothyroidism (Varghese and Oommen, 1999; Varghese et al., 2001). Low thyroxin level in hypothyroid animals not only triggered enhanced thyrotropin secretion from pituitary but also stimulates corticotrophin, and in turn, adrenal steroids, thereby increases lipid mobilization through overlapping endocrine axis (Mc-Donald, 1980). In fact, hypercholesteremia, hyperlipidemia and increase in body weight have been suggested as excellent indicators of decreased thyroid function (Al-Tonsi et al., 2004). Interestingly, in our study all these PTU induced adverse effects including increase in body weight were ameliorated by the simultaneous administration of PQQ, clearly suggesting the potential of test drug in ameliorating hypothyroidism.

Since nothing was known on the role of PQQ in regulating hypothyroidism, our study can be compared with the other antioxidative plant based active compounds, which were also found to be beneficial in the regulation of hypothyroidism in animal model (Panda and Kar, 2005; Jatwa and Kar, 2009). In fact, till to date no literature is available in relation to the role of PQQ in the regulation of thyroid dysfunction. Therefore, the present report appears to be the first one that clearly indicates the efficacy of PQQ in regulating PTU induced adverse effects / hypothyroidism. PQQ was earlier known to regulate different abnormalities including cardiac problems (Zhu et al., 2004), which are often related with thyroid dysfunctions. Now our findings ascertain that PQQ has the potential to regulate PTU induced adverse effects / hypothyroidism. The possible mechanism of its 
efficacy to ameliorate PTU induced oxidative stress could be its strong antioxidant properties, as suggested in some previous studies, in which the free radical scavenging activity of PQQ has been clearly shown (Ouchi et al., 2009; Misra et al., 2012). Whatever may be the mechanism of action, from our present findings it is clearly evident that PQQ has the potential to ameliorate PTU induced oxidative stress and it may work against hypothyroidism, although for human therapy point of view, further investigation is required.

\section{Acknowledgement}

Financial support from the Council of Scientific and Industrial Research (CSIR), New Delhi, India for a Junior Research fellowship to Narendra Kumar is gratefully acknowledged.

\section{References}

[1] Aebi HE(1983): Catalase. In: Bergmeyer HU (ed.). Methods in Enzymatic Analysis. Academic Press, New York. $276-86$.

[2] Aizenman E, Hartnett KA, Zhong C, Gallop PM, Rosenberg PA(1992): Interaction of the putative essential nutrient pyrroloquinoline quinone with the N-methyl-D-aspartate receptor redox site. J Neurosci. 12:2362-69.

[3] Allain CC, Poon LS, Chan CS, Richmond W, fu PC(1974): Enzymatic determination of total serum cholesterol. Clin Chem.20:47075.

[4] Al-Tonsi AA, Abdel-Gayoum AA, Saad M (2004): The secondary dyslipidemia and deranged serum phosphate concentration in thyroid disorders. Exp Mol Pathol. 76:182-7.

[5] Ameyama M, Matsushita K, Ohno Y, Shinagawa E, Adachi O(1981): Existence of a novel prosthetic group, PQQ, in membranebound, electron transport chain-linked, primary dehydrogenases of oxidative bacteria. FEBS Lett. 130:179-83.

[6] Amin A, Hamza AA (2005): Oxidative stress mediates drug-induced hepatotoxicity in rats: a possible role of DNA fragmentation. Toxicology. 208:367-75.

[7] Andrea CR, Antonio R, Augusto R, Enrico S(1999): Modeling novel quinocofactors: An overview. Bioorg Chem. 27:253-88.

[8] Asayama K, Dobashi K, Hayashibe H, Megata Y, Kato K (1987): Lipid peroxidation and free radical scavengers in thyroid dysfunction in the rat: a possible mechanism of injury to heart and skeletal muscle in hyperthyroidism. Endocrinology. 121:211218.

[9] Asayama K, Kato K (1990): Oxidative muscular injury and its relevance to hyperthyroidism. Free Radic Biol Med. 8:293-303.

[10] Bishop A, Gallop PM, Karnovsky ML (1998): Pyrroloquinoline quinone: a novel vitamin? Nutr Rev. 56:287-93.

[11] Carmeli E, Bachar A, Barchad S, Morad M, Merrick J (2008). Antioxidant status in the serum of personswith intellectual disability and hypothyroidism: Apilot study. Res. Development. Disab. 29:431-38.

[12] Choi O, Kim J, Kim JG, Jeong Y, Moon JS, Park CS (2008) Pyrroloquinoline quinone is a plant growth promotion factor produced by Pseudomonas fluorescens B16. Plant Physiol. 146:657-68.

[13] Dariyerli N, Toplan S, Akyolcu MC, Hatemi H, Yigit G (2004): Erythrocyte osmotic fragility and oxidative stress in experimental hypothyroidism. Endocrine. 25:1-5.

[14] Das K, Chainy GB (2001): Modulation of rat liver mitochondrial antioxidant defence system by thyroid hormone. Biochim. Biophys. Acta. 1537: 1-13.

[15] Duine JA, Frank J (1981): Quinoprotein alcohol dehydrogenase from a non-methylotroph, Acinetobacter calcoaceticus. J Gen Microbiol. 122:201-9.

[16] Ellman GL (1959): Tissue sulfhydryl groups. Arch Biochem Biophys. 82:70-77.

[17] Feng X, Jiang Y, Melzer P, Yen P M (2000): Thyroid hormone regulation of hepatic genes in vivo detected by complementary DNA microarray. Mol Endocrinol. 14:947-55.

[18] Ganong WF (2005): Review of Medical Physiology. 22nd edn. Appleton \& Lange, Connecticut.

[19] Guerrero A, Pamplona R, Postero-Otin M, Barja G, Lopez-Torres M (1999): Effect of thyroid status on lipid composition and peroxidation in the mouse liver. Free Rad Biol Med. 26:73-80.

[20] Hamagishi Y, Murata S, Kamei H, Oki T, Adachi O, Ameyama M (1990): New biological properties of PQQ and its related compounds: inhibition of chemiluminescence, lipid peroxidation and rat paw edema. J Pharmacol Exp Ther. 255:980-85.

[21] He K, Nukada H, Urakami T, Murphy MP (2003): Antioxidant and pro-oxidant properties of pyrroloquinoline quinone (PQQ): implications for its function in biological systems. Biochem Pharmacol. 65:67-74.

[22] Isman CA, Yegen BC, Alican I (2003): Methimazole-induced hypothyroidism in rats ameliorates oxidative injury in experimental colitis. J Endocrinol. 177:471-76.

[23] Jatwa R, Kar A (2009): Amelioration of metformin-induced hypothyroidism by Withania somnifera and Bauhinia purpurea extracts in type 2 diabetic mice. Phytoth Res. 23:1140-5.

[24] Jena S, Dandapat J, Chainy GB (2012): Curcumin differentially regulates the expression of superoxide dismutase in cerebral cortex and cerebellum of L: thyroxine (T4) induced hyperthyroid rat brain Neurol Sci. 34:505-10.

[25] Jensen FE, Gardner GJ, Williams AP, Gallop PM, Aizenman E, Rosenberg PA (1994): The putative essential nutrient pyrroloquinoline quinone is neuroprotective in a rodent model of hypoxic/ischemic brain injury. Neurosci. 62:399-406.

[26] Khairnar NP, Kamble VA, Mangoli SH, Apte SK, Misra HS (2007): Involvement of a periplasmic protein kinase in DNA strand break repair and homologous recombination in Escherichia coli. Mol Microbiol. 65:294-304.

[27] Knapp M, Lisowska A, Sobkowicz B, Tycińska A, Sawicki R, Musiał WJ (2013): Myocardial perfusion and intima-media thickness in patients with subclinical hypothyroidism. Adv Med Sci. 58:44-49.

[28] Kobayashi K, Mustafa G, Tagawa S, Yamada M (2005): Transient formation of a neutral ubisemiquinone radical and subsequent intramolecular electron transfer to pyrroloquinoline quinone in the Escherichia coli membrane-integrated glucose dehydrogenase. Biochemistry. 44:13567-72.

[29] Kundu S, Pramanik Roy S, De J, Biswas A, Ray AK (2006): Maintenance of brain thyroid hormone level during peripheral hypothyroid condition in adult rat. Life Sci. 79:1450-55.

[30] Lindeman RD (1990): Overview: renal physiology and pathology of aging. Am J Kidney Dis. 4:275-82.

[31] Lowry OH, Rosebrough NJ, Farr AL, Randal RJ (1951): Protein measurement with the Folin phenol reagent. J Biol Chem.193:26575.

[32] Marklund S, Marklund G (1974): Involvement of superoxide anion radical in the autoxidation of pyrogallol: A convenient assay for superoxide dismutase. Eur J Biochem. 47:469-74.

[33] Mc Donald LE (1980): Veterinary endocrinology and reproduction, 3rd ed. London: Lea and Febiger, Philadephia/Balliere Jindall Publication; pp. 42-59. 
[34] Messarah M, Boumendjel A, Chouabia A, Klibet F, Abdennour C, Boulakoud MS et al.,(2010) Influence of thyroid dysfunction on liver lipid peroxidation and antioxidant status in experimental rats. Exp Toxicol Pathol. 62:301-10.

[35] Misra HS, Khairnar NP, Barik A, Indira Priyadarsini K, Mohan H, Apte SK (2004): Pyrroloquinoline-quinone: a reactive oxygen species scavenger in bacteria. FEBS Lett. 578:26-30.

[36] Misra HS, Rajpurohit YS, Khairnar NP (2012): Pyrroloquinoline-quinone and its versatile roles in biological processes. J Biosci 37:313-25.

[37] Montenegro J, Gonzalez O, Saracho R, Aguirre R, Gonzalez O, Martinez I (1996): Changes in renal function in primary hypothyroidism. Am J Kidney Dis. 27:195-98.

[38] Nanda N, Bobby Z, Hamide A, Koner BC, Sridhar MG (2007): Association between oxidative stress and coronary lipid risk factors in hypothyroid women is independent of body mass index. Metabolism. 56:1350-55.

[39] Norris DO (1969): Depression of growth following radiothyroidectomy of larval Chinook salmon and steelhead trout. Trans Am Fish Soc. 98:104-6.

[40] Ohkawa H, Ohishi N, Yagi K (1979):. Assay of lipid peroxides in animal tissues by thiobarbiturie acid reaction. Anal Biochem 95:351-58.

[41] Ouchi A, Nakano M, Nagaoka S, Mukai K (2009): Kinetic study of the antioxidant activity of pyrroloquinolinequinol (PQQH(2), a reduced form of pyrroloquinolinequinone) in micellar solution. J Agric Food Chem. 57:450-56.

[42] Panda S, Kar A (2005): Guggulu (Commiphora mukul) potentially Ameliorates Hypothyroidism in female mice. Phytoth Res. 19:78-80.

[43] Plisetskaya E, Woo NYS, Murat J (1983): Thyroid hormones in cyclostomes and fish and their role in regulation of intermediary metabolism. Comp Biochem Physiol A Mol Integr Physiol.74:179-87.

[44] Qiu XQ, Liu CL, Xu L, Zhao JY, Wu SL (2009): Effect of pyrroloquinoline quinone on antioxidative competence of AGS cell radiated by $\gamma$-ray. J Jiangsu Univ (Med. Ed.) 19:293-95.

[45] Rajpurohit YS, Gopalakrishnan R, Misra HS (2008): Involvement of a protein kinase activity inducer in DNA double strand break repair and radioresistance of Deinococcus radiodurans. J Bacteriol. 190:3948-54.

[46] Reitmen S, Frankel S (1957): Acolorimetric method for the determination of serum glutamic oxaloacetic and glutamic pyruvic transaminase. Am J Clin Pathol. 28:56-63.

[47] Rucker R, Chowanadisai W, Nakano M (2009): Potential Physiological Importance of Pyrroloquinoline Quinone. Altern. Med Rev. 14:268-77.

[48] Salisbury SA, Forrest HS, Cruse WB, Kennard O (1979): A novel coenzyme from bacterial primary alcohol dehydrogenases. Nature 280:843-44.

[49] Sheridan MA, His Kao Y (1998): Regulation of metamorphosis associated changes in the lipid metabolism of selected vertebrates. Am Zool. 38:350-68.

[50] Shrivastava M, Rajpurohit YS, Misra HS, D’Souza SF(2010): Survival of phosphate-solubilizing bacteria against DNA damaging agents. Can J Microbiol. 56:822-30.

[51] Sies H (1999): Glutathione and its role in cellular functions. Free Radic Biol Med. 27:916-21.

[52] Simon-Giavarotti KA, Giavarotti L, Gomes LF, Lima AF, Veridiano AM, Garcia EA, et al., (2002): Enhancement of lindaneinduced liver oxidative stress and hepatotoxicity by thyroid hormone is reduced by gadolinium chloride. Free Radic Res. 36:10339.

[53] Smidt CR, Steinberg FM, Rucker RB (1991): Physiologic importance of pyrroloquinoline quinine. Proc Soc Exp Biol Med. 197:1926.

[54] Snedecor GW, Cochran WG (1956): Statistical methods applied to experiments in agriculture and biology. 5th ed. Ames, Iowa: Iowa State University Press, pp 534.

[55] Tao R, Karliner JS, Simonis U, Zheng J, Zhang J, Honbo N, Alano CC (2007): Pyrroloquinoline quinone preserves mitochondrial function and prevents oxidative injury in adult rat cardiac myocytes. Biochem Biophys Res Commun. 363:257-62.

[56] Tas S, Dirican M, Sarandol E, Serdar Z (2006): The effect of taurine supplementation on oxidative stress in experimental hypothyroidism. Cell Biochem Funct. 24:153-58.

[57] Trinder P (1969): Determination of blood glucose using an oxidase-peroxidase system with a non-carcinogenic chromogen. J of Clin Pathol. 22:158-61.

[58] van Kleef MAG, Duine JA (1988): L-Tyrosine is the precursor of PQQ biosynthesis in Hypomicrobium X. FEBS Lett. 237:91-97.

[59] Varghese S, Oommen OV (1999): Thyroid hormones regulate lipid metabolism in teleost Anabas testudinens (Bloch). Comp Biochem Physiol. 124:445-50.

[60] Varghese S, Shameena B, Oommen OV (2001): Thyroid hormones regulate lipid peroxidation and antioxidant enzyme activities in Anabas testudinens (Bloch). Comp Biochem Physiol. 128:165-71.

[61] Venditti P, Balestrieri M, Di Meo S (1997): Effect of thyroid state on lipid peroxidation, antioxidant defences, and susceptibility to oxidative stress in rat tissues. J Endocrinol. 155:151-57.

[62] Venditti P, Di Meo S (2006): Thyroid hormone-induced oxidative stress. Cell Mol Life Sci.63:414-34.

[63] Wahlqvist ML, Fidge NH, Lomas F (1977): Lipoprotein composition in hypothyroidism. Clin Chim Acta. 77:269-74.

[64] Wu QS, Wang JH, Zhou YH, Qin F, Shen L, Wu SL (2008): Effect of pyrroloquinoline quinoneon free radical in rats with radiation induced skin injury. J Jiangsu Univ (Med. Ed.)18:403-5.

[65] Xiong XH, Zhi JJ, Yang L, Wang JH, Zhao Y, Wang X, et al., (2011): Complete genome sequence of the bacterium Methylovorus sp. strain MP688, a high-level producer of pyrroloquinolone quinone. J Bacteriol. 193:1012-13.

[66] Yamaguchi K, Sasano A, Urakami T, Tsuji T, Kondo K (1993): Stimulation of nerve growth factor production by pyrroloquinoline quinine and its derivatives in vitro and in vivo. Biosci Biotechnol Biochem. 57:1231-33.

[67] Yilmaz S, Ozan S, Benzer F, Canatan H (2003): Oxidative damage and antioxidant enzyme activities in experimental hypothyroidism. Cell Biochem Funct. 21:325-30.

[68] Zhu B, Zhou H, Teerlink JR, Karliner JS (2004): Pyrroloquinoline Quinone (PQQ) Decreases Myocardial Infarct Size and Improves Cardiac Function in Rat Models of Ischemia and Ischemia/Reperfusion. Cardiovasc Drugs Ther.18:421-31. 